\title{
Body Language in Business Negotiation
}

\author{
Hui Zhou \& Tingqin Zhang \\ Daqing Petroleum Institute at Qinhuangdao, Qinhuangdao 066004, China
}

\begin{abstract}
Human beings communicate through a variety of channels. Language is not the sole means by which humans exchange information. In conversation, we express our ideas and feelings not only with words but also through facial expressions, voice tones, and gestures. These non-verbal languages are called "Body Language". It is just like our verbal language, is also a part of our culture.

In business negotiations, body language plays a significant role in the communication. It is necessary to master the skills of using and reading body language. This article mainly discusses the art of body language in negotiation. It states its functions and importance in business negotiations, then explores how to use and understand body language in negotiations. Different people have different ways of making nonverbal communication. A comparative study of Chinese and American body language shows a number of similarities and diversities of body language. It shows the importance of knowing the specific signals that go together with a language. It finally emphasizes the necessity and importance of learning body language in non-verbal communication and business negotiations.
\end{abstract}

Keywords: Body language, Negotiation, Different culture, Different ways

\section{Introduction}

Some studies show that up to 90 percent of communication is nonverbal. Though you might say one thing, your body movements may indicate something entirely different. All types of language that take place without words are defined as nonverbal language. Language that doesn't use words takes place all the time. When we converse with others we communicate by much more than words. By our expressions, gestures and other body movements we send messages to these around us a smile and an outstretched hand show welcome. A frown is a sign of displeasure. Nodding one's head means agreement- "Yes". Waving an outstretched hand with open palm is the gesture for "Goodbye". Leaning back in one's seat and yawning at a talk or lecture shows lack of interest, boredom.

Many people may think that to have a successful negotiation, the negotiators must master the language skills of negotiation and bargaining, to some extent, they are right. But that is far more enough. In fact, many negotiators are not aware that they communicate nonverbally. Most nonverbal messages are involuntarily. Verbal language really play important role in negotiations, but it is not the only means by which negotiators exchange information. In negotiation, for example, negotiators express their ideas and feelings not only with words, but also through facial expressions, voice tones and gestures. Even clothing and grooming may send message of one kind or another to others. Some experts say only 30 percent of communication comes from talking. Your gestures and other nonverbal actions matter too. An old saying goes: "actions speak louder than words." That's true according to communication experts.

\section{The definition of body language and the necessity and importance of learning body language in negotiation}

We all instinctively give gestures and facial expressions which reveal our inner thoughts. It's hardwired into our brains and stretches back to our earliest days in the cave when facial expressions and gestures were all we had to communicate with. Like music tracks on a CD these communication tools have been burned into our brains. Our body language becomes part of our conversation. It sends signals to another person about us. Present ourselves with confidence and authority and practice good posture. Stand with our back straight, shoulders back, and our chin up. Our voice does not sound clear when our chin is dropped toward our chest. Keep our arms relaxed at our side and avoid clasping our hands behind our back or hugging our arms in front. Portray calmness. Avoid nervous gestures such as tapping our foot or jingling coins in our pocket or playing with a pen. Keep our hands off our face and never pick at our nose. The way we walk and the way we talk all tell something about our social status. These gestures have come to be accepted in general as having the meanings mentioned, at least to Chinese and Americans.

\subsection{The definition of body language}

As we mentioned earlier, it is impossible for us to stop communicating non-verbally. We all lean, point and look away. We move our hands to emphasize in our talk. We frown, smile, fold our arms, and move toward objects or people, then move away. How we stand, walk, eat, and gesture reveals much about our personality. It is called "body language". It is an important media through which people communicate with each other. It refers to the patterns of facial expressions and gestures that people use to express their feelings in communication. 
"Body language" also defined as the nonverbal communication or the communicative functions of body, it is also called kinesics. It is part of the way in which we communicate. This "body language", like our verbal language, is also a part of our culture.

\subsection{The necessity and importance of learning body language in negotiation}

It is an extremely powerful tool which can improve our life in many ways. With patience, persistence, and practice we can use nonverbal behavioral patterns to more easily detect truth and lies, project a more confident, powerful presence, persuade, influence, and sell better, put people at ease, create a sense of trust, make friends. It is especially important in business negotiations. If you are only aware of a negotiator's verbal message, you will likely miss the major portion of the overall communication. Being aware of both nonverbal and verbal messages will give you an important edge.

Communication is more than verbal. Good negotiators must first be good communicators. Unfortunately, many negotiators think of communication only as oral or written verbal exchanges. But verbal exchanges account for only a fraction of the messages people send and receive. Research has shown that between 70 and 90 percent of the entire communication spectrum is nonverbal. Consequently, you should be aware of the different forms of nonverbal communication that you are likely to encounter during negotiation conferences.

\section{The concrete types and application of the body language in negotiation}

\subsection{Types of body language}

Body language or kinesics can be understood by recognizing the following six important aspects.

\subsubsection{Distance between people conversing}

Watch an Arab and an Englishman in negotiation. The Arab, showing friendliness in the manner of his people, will stand close to the Englishman. The latter will move back, watching to the Englishman. The Arab will then move forward to be closer; the Englishman will keep moving backward. By the end of the negotiation, the two may be quite a distance from the negotiation; the two may be quite a distance from the place where they were originally standing!

Here, distance between the two is the key factor. Different people have different ideas about the proper distance between people conversing. According to studies, it seems there are four main distances in American social and business relations: intimate, personal, social, and public. Intimate distance ranges from direct physical contact to a distance of about 45 centimeters; this is for people's most private relations and activities, between man and wife, for example. Personal distance is about 45-80 centimeters and is most common when friends, acquaintances and relatives converse. Social distance may be anywhere from about 1.30 meters to 3 meters; people who work together, or people doing business, as well as most of those in conversation at social gatherings tend to keep a distance is farther than any of the above and is generally for speakers in public and for teachers in classrooms.

The important thing to keep in mind is that most English-speaking people do not like people to be too close. In negotiations being too far apart, of course, may be awkward, but being too close makes people uncomfortable, unless there is a reason, such as showing affection or encouraging intimacy. But that is another matter.

\subsubsection{Physical appearance and physical contact}

Physical appearance conveys messages. It plays a very important role in creating first impression. You need be aware of the effect that your physical appearance may have on nonverbal communication. Awareness may permit you to build on your natural advantages. However, awareness of any natural disadvantage may be even more important.

Research has found that:

Physical attractiveness affects the way you perceive yourself and the way other perceive you.

Personal Dress: The importance of how we dress is highlighted by the cliché, "Dress for success." Clothing has been found to affect perceptions of credibility, likeability, attractiveness, and dominance, but researchers agree that clothing has the most potent affect on credibility.

Unfortunately, many otherwise good negotiators ignore the importance of personal dress during negotiations, and that ignorance negatively affects their ability to attain mutually satisfactory negotiation results.

In English-speaking countries, physical contact is generally avoided in conversation among ordinary friends or acquaintances. Merely touching someone may cause an unpleasant reaction. If one touches another person accidentally, he/she usually utters an apology such as "Sorry, Oh, I'm sorry, Excuse me."

In China, a common complaint of western mothers is that Chinese often fondle their babies and very small children. 
Such behavior-whether touching, patting, hugging or kissing — can be quite embarrassing and awkward for the mothers. They know that no harm is meant, and that such gestures are merely signs of friendliness or affection, therefore they cannot openly show their displeasure. On the other hand, such actions in their own culture would be considered rude, intrusive and offensive and could arouse a strong dislike and even repugnance. So the mothers often stand by and watch in awkward silence, with mixed emotions, even when the fondling is by Chinese friends or acquaintances.

The matter of physical contact between members of the same sex in English-speaking countries is a delicate one. Once past childhood, the holding of hands, or walking with an arm around another's shoulder is not considered proper. The implication is homosexuality, and homosexuality generally arouses strong social disapproval in these countries.

\subsubsection{Eye contact}

Eye contact is an important aspect of body language. One could draw up quite a list of "rules" about eye contact: to look or not to look; when to look and how long to look; who and who not to look at.

There are different formulas for the exchange of glances depending on where the meeting takes place. If you pass someone in the street you may eye the oncoming person till you are about eight feet apart, then you must look away as you pass. Before the eight-foot distance is reached, each will signal in which direction he will pass. This is done with a brief look in that direction. Each will veer slightly, and the passing is done smoothly."

In conversations with people who know each other, however, American custom demands that there should be eye contact. This applies to both the speaker and the listener. For either one not to look at the other person could imply a number of things, among which are fear, contempt, uneasiness, guilt, indifference, even in public speaking there should be plenty of eye contact. For a speaker to "burry his nose in his manuscript", to read a speech instead of looking at and talking to hid audience, as some Chinese speakers are in the habit of doing, would be regarded as inconsiderate and disrespectful.

In conversation, a person shows that he is listening by looking at the other person's eyes or face. If the other person is speaking at some length, the listener will occasionally make sounds like "Hmm", "Ummm", or nod his head to indicate his attention. If he agrees with the speaker, he may nod or smile. If he disagrees or has some reservations, he may slant his head to one side, raise an eyebrow, and have a quizzical look.

Staring at people or holding a glance too long is considered improper in English-speaking countries. Even when the look may be one of appreciation—as of beauty_it may make people uneasy and embarrassed. Many Americans traveling abroad find the stares of the local people irritating. They become extremely self-conscious and often end up quite indignant about the "rudeness" of the people there, not realizing that the practice may be quite common in the country and may be nothing more than curiosity. Many English-speaking people in china have heard to complain about this.

The difference in interpreting a simple eye gesture was a lesson in cultural diversity that we would not easily forget. For example, Chinese avoid long direct eye contact to show politeness, or respect, or obedience, while North Americans see eye contact as a sign of honesty and a lack of eye contact or shift eyes as a sign of untruthfulness. Though speaking the same language, the British, unlike the Americans, believe that looking someone directly on the eye to be a mark of rudeness until a more familiar relationship is established. An American businesswoman told a story that they (Americans) felt as if the British were hiding something because none of them would look them in the eye throughout the presentation. The failure of the British to look her in the eye almost "ruined the relationship and suck the deal," she said. "I understand it now, but I still don't like it".

The amount of eye contact varies greatly among cultures. For example, in business meetings, the French will demand at least some direct eye contact. To refuse to meet someone's eyes an unfriendly gesture. Compare this to the attitude of Japanese, who believe that the less eye contact, the higher the level of esteem. To divert eyes from a business colleague is a sign of respect and reverence.

Rules about eye-language are numerous and complex. What has been mentioned gives a good idea of this; we shall not go further into detail.

\subsubsection{Facial expression}

As the most expressive part of the body, the face is probably the single most important source of non-verbal communication. It is capable of conveying several emotions simultaneously. The face not only can communicate a great deal, but also seemed to be the type of non-verbal behavior that people are beat able to control. However, facial expressions should be interpreted in cultural context and with caution. Take for example smiles and laughter. 
Smiles and laughter usually convey friendliness, approval, satisfaction, pleasure, joy and merriment. This is generally true in China as well as the English-speaking countries. However, there are situations when some Chinese will laugh that will cause negative reactions by westerners.

Other facial expressions also vary from culture to culture. For instance in some US businesses, it is considered acceptable to frown, swear, and yell, but not to cry. But for the Japanese in situations of strong emotion it is considered acceptable to smile or laugh, but not to frown or cry.

\subsubsection{Gestures}

Gesture is the expressive movement of a part of the body, especially the hand and the head. People talk with their hands, but what they mean depends on their culture. As with verbal language, non-verbal codes are not universal. Same gestures have different meanings in different cultures.

The forefinger near lips with the sound "shah", which is a sign for silence in UK and America, means disapproval, hissing in China.

In different cultures different gestures are used for the same meaning. For coming here, Chinese gesture is a hand extended toward the person, open palm, fingers crooked in a beckoning motion; the American is a hand extended toward person, close hand, palm up, with forefinger only moving back and forth. For Americans, the Chinese coming-here gesture is like good-bye gesture. Many Chinese would see American coming-here gesture as offensive.

The same is true with some commonly used gestures. The OK sign (the circle formed with the thumb and first finger), which has the similar meaning in most of Western Europe, is a vulgar insult in Greece, an obscene gesture in Brazil, Mediterranean countries and Southern Italy, a sign for the sex act in some Latin American nations and can mean "you're worth nothing" in France and Belgium .

Like hand movements, head movements differ from one culture to another. In Bulgaria, for example, people may nod their heads to signify no and shake their heads to signify yes. So gestures can be very confusing inter-culturally. But there are some gestures that have widely understood meanings. For example, foot-shaking, finger-tapping and fidgeting with a tie or hair usually signify nervousness or boredom; a clench fist typically indicates hostility or aggression.

Specialists in the study of body movement emphasize that no single gesture carries meaning in and of itself. The gestures just discussed do not always mean the same thing. To understand a person's meaning, pay attention to all the cues they are sending and the context in which the cues occur, not to just a single gesture.

When one communicate in a certain language, it is generally advisable to use the non-verbal behavior that goes with that particular language.

\subsubsection{Posture}

The way people carry themselves communicates volumes. People from different cultures learn to sit, to walk and to stand differently. The impact of culture on non-verbal communication is so strong that even people with great experience in cross-culture communication might be unaware of how meaning of a non-verbal act varies from culture to culture. The wife of a former president of the United States was said to have shocked her Arab hosts by crossing her legs during a public meeting, which is an indecent posture in Arab culture.

Posture offers insight into a culture's deep structure. For instance, in the United States where being casual and friendly is valued; people often fall into chairs and slouch when they stand. In many European countries, such as Germany, where lifestyle tends to be more formal, a slouching posture is considered a sign of rudeness and poor manners. Similarly, in Japan, the formality is important and the Japanese value the ability to sit quietly. They might see the Americans fidget and shift as an indication of lack of mental or spiritual balance.

But there are similarities. For instance, even in North America, swinging a foot in interview makes negative impression. Also, people respond unfavorably to standing with weight back on heels and hands in pockets at work place or sitting with feet up on the desk in office. And slouching or leaning on the lectern in business presentation may make the audience feel that the speaker's ideas area as careless as his or her posture,

Generally, standing erect, shoulders back, head held high display confidence, energy, and self-assurance, which gains more attention from the audience. And a relaxed posture, a comfortable seating position, uncrossed arms, and lack of stiffness indicate openness with no communication obstacles. On the other hand, abrupt movements, shifting seating positions, crossed arms or legs may signal defiance, disinterest or an unwillingness to listen.

Women in many settings will often hold their arms closer to their bodies than men. They will also keep their legs close together and seldom cross them in mixed company. 


\subsection{Application of the body language in negotiation}

Good negotiators know how to use body language to their advantage. They also know how to read other people's body language to gain the upper hand. Crossed arms, raised eyebrows, wandering eyes - they all mean something. Pay attention and you'll be surprised what you might learn about what is really going on in the negotiation regardless of what is being said with words.

\subsubsection{Body language affects negotiation}

Body Language and Attitudes: Body language research has catalogued 135 distinct gestures and expressions of the face, head, and body. Eighty of these expressions were face and head gestures, including nine different ways of smiling. These gestures and expressions provide insight into the attitude of the originator. Simultaneous physical signals often reinforce each other and reduce the ambiguity surrounding the message. For example, eagerness is often exhibited with the simultaneous physical displays of excessive smiling along with frequent nodding of the head.

Common attitudes communicated nonverbally during negotiations can be grouped into two broad classifications—-positive attitudes and negative attitudes.

Positive Attitudes: Positive attitudes indicated by body language may signal a sincere effort to achieve win/win results. Key indicators of positive attitudes are listed below.

Gestures: Be particularly careful when you are interpreting or using gestures. A gesture that means one thing in one society can mean something completely different in another. There is a good chance that you will encounter differing interpretations whenever you are negotiating with someone from another part of the world. Even if the other party is from the United States, some of these differing interpretations may remain as part of the person's heritage.

(1) Shaking your head up-and-down means "yes" in the United States and left-to-right means "no". In some parts of the world the meanings are just the opposite.

(2) The hand signal for O.K. in the United States is an obscene gesture in some societies.

(3) The thumbs-up gesture is a positive sign in most of the world, but in some cultures it considered a rude gesture.

(4) The V-shaped hand gesture with the index finger and middle finger may mean victory or peace in the United States, but in some countries it could be interpreted as an obscene gesture.

\section{How to use and understand body language in negotiation}

\subsection{How to use body language in negotiation}

Using nonverbal communication can manage yourself and others. In negotiations, once you become aware of your counterpart's body language, you can change your own nonverbal communication. By putting your notepad on the table, sliding forward in your seat, and uncrossing your legs, you can change your position to a much more receptive one. Once you begin to manage your nonverbal behavior and that of your counterpart, you will start reaping the benefits of "speaking the language." Body language reflects people's true feelings. The better you understand that language, the more you will be able to use it to your advantage.

In contract negotiation, you can use the knowledge of body language in several ways:

As you prepare for the negotiation conference, you should briefly review key elements of body language with members of the Government team.

The most important observation you can make about a room full of people is the personal space each person commands. Human nature dictates that people considered more powerful are typically awarded greater personal space by the other people in the room.

Control over the dominant chair (usually the head of the table) may be the most obvious sign of power. Remember Archie Bunker? He didn't control a clear position of power at work, so his chair became a symbol of his status at home.

Once the spatial relationships are established, they are not easy to change. Take a moment before your next meeting and think about what relationship you want to establish with the other attendees. Arrange the seating accordingly.

Making first contact

Begin every meeting with great body language. Let your enthusiasm and energy show. Meet the other person's eyes and give a good, firm handshake. Let the flesh between your thumb and forefinger meet the other person's flesh between the thumb and forefinger. Press-do not squeeze- the hand. One pump accompanied by eye contact is 
plenty. One or two more may express great enthusiasm; any more than that can make the person uncomfortable.

Women greeting women in America can touch both hands at the same time as an alternative to a handshake.

Handshaking is far from uniform around the world. Germans are a nation of one-pump people. The French often shake one hand while putting the other on the opposing shoulder. The Japanese may forego the handshake for a bow.

\section{Gauging reception}

If you pay attention to body language early in a negotiation, you can spot signals of how receptive (how ready to listen and how open to your ideas) your counterpart is. Table 1 shows the positive and negative cues associated with being receptive and unreceptive.

Legs and feet Sitting: Legs together, or on in front of the other slightly (as if at the starting line of a race). Standing: Weight evenly distributed, body tilted toward the speaker. Standing: Crossed legs, pointing away from the speaker. Sitting or standing: Legs and feet pointing toward.

Receptive people look relaxed with open hands, displaying the palms, indicating openness to discussion. They lean forward, whether they are sitting or standing. Receptive negotiators unbutton their coats. By contrast, people who aren't willing to listen may lean back in the chair or protectively fold their arms across their chest. Having one leg up on the arm of the chair appears to be an open posture, but more often, this position signals a lack of consideration.

\section{Seeing a change of heart}

Observing how someone is sitting or standing is the first step in reading body language — but people aren't frozen like statues. Their positions and gestures change with their attitudes and emotions. Notice these shifts.

Looking out the window, holding the head up with one hand, doodling in a way that seems to absorb the doodler's complete attention, drumming fingers on the table all indicate that the listener is no longer paying attention.

One more thing to keep in mind: Body language works both ways. If your opponent is an experienced negotiator, chances are good that he or she will be observing your posture, gestures, breathing patterns, etc. Be aware of this and try to use it to your advantage. By using your body to transmit the appropriate message to your negotiating opponent, you can enhance the chances of securing the right deal and, just as importantly, keeping the negotiation amicable.

\subsection{How to understand body language in negotiation}

Learning the language of nonverbal communications is almost as difficult as acquiring fluency in a foreign language. Reading body language is perhaps the most powerful form of human communication! And armed with the right information about reading body language, you can almost read people's minds. In addition to studying your own gestures and the meaning you are conveying, you must also become aware of what your counterpart is conveying.

\subsubsection{Gesture Clusters}

Many skeptics argue that it is difficult to tell what someone is thinking by singling out one gesture-and they are right. A single gesture is like a single word; its true meaning is difficult to understand out of context. However, when gestures come in clusters, their meaning becomes clearer. For example, while a person's fidgeting may not mean much by itself, if that person is avoiding eye contact, holding his hands around his mouth, touching his face and fidgeting, there's a good chance he is not being totally honest.

Involuntary hand movements can be particularly telling. People often touch their nose, chin, ear, arm or clothing when they are nervous or lack confidence in what they are saying.

Legs: When asked why they cross their legs, most people say they do so for comfort. Although they are being truthful, they are only partially correct. If you have ever crossed your legs for a long period of time, you know that this position can become painfully uncomfortable.

Studying what you and your counterpart in the negotiation process are not saying is critical to achieving a win/win outcome. The following chart is a "dictionary" that will help you translate your counterpart's body language, and use your own to say what you really mean to say.

\section{Conclusion}

The study of body language should be complementary to the study of language in communications. The understanding of one should be helpful in the further understanding of the other. Some authorities feel that the two are dependent on each other. This is certainly true in most situations. But it is also true that in certain situations body action contradicts what is being said, just as the spoken words may mean something quite different from what body 
language communicates. When this occurs, one must try to get further information, or guess the meaning from the context of the situation. In a sense, all body language should be interpreted within a given context; to ignore the overall situation could be misleading.

A word of general advice: when one negotiate in a certain language, it is generally advisable to use the nonverbal behavior that goes with that particular language. Observation shows that a truly bilingual person switches his body language at the same time he switches languages. This makes negotiation easier and better.

A powerful piece of body language which you can have control over is the closeness between you and the buyer. To conclude a negotiation there needs to be a feeling of connection. If the buyer is well away from his desk or leaning back, place some brochures on the table but sufficiently far away that he has to come closer to you. You should then mirror his action and move closer as well. The end result is that you will be in a better position to strike a deal.

Trying to spot the body language, listen to what is being said and deciding what your next action takes practice and patience.

\section{References}

Fast Julius. (1971). Body Language. Pocket Books. N.Y.: Random House Value Publishing, Inc.

Jamesw .H ALL . (1994). Body Language. Chicago: The University of Chicago Press.

J o Toole. (1992). The Process of Drano: Negotiation Art and Meaning. London: Folcroft Library Editions.

Liu, Yongfa \& Liu, Xuan'en. (1997). The Practical Body Language. BeiJing: Hua Wen Press.

RE Axtell. (1991). The Do's and Taboo's of Body Language. Boston: James Munroe.

Robinett, Betty W. (1978). Teaching English to speakers of other Language: Substance and Technique. N.Y.: McGraw-hill.

Samovar L. A. (1981). Understanding Intercultural Communication. London: Wadsworth Publishing Company. Shen Minxian. (1999). The Use of the Body Language in Elementary School. Shanghai: Shanghai Education Vol.

Stern H. H. (1983). Fundamental Concepts of Language Teaching. London: Oxford University press.

T Morrison, WA Conaway \& GA Borden. (1994). How to Do Business in Sixty Countries. Oxford: Oxford University Press. 